\title{
Male morph determination in two species of acarid mites
}

\author{
JACEK RADWAN* \\ Department of Zoopsychology and Animal Ethology, Institute of Environmental Biology, Jagiellonian University, ul \\ Ingardena 6, 30-060 Krakow, Poland
}

\begin{abstract}
Male morph was found to be determined in different ways in two species of acarid mites within which morphologically distinct fighter and nonfighter males occur. Fighter males sired significantly larger proportions of fighters in comparison to nonfighter males in Rhizoglyphus robinii, but not in Caloglyphus berlesei. The genetic mechanism of male morph determination in $R$. robinii remains unclear: neither single-locus nor polygenic models fit the results of the crosses. Mites fed on a poor diet during development were less likely to develop into fighters in both species. However, increased density inhibited the development of fighters in $C$. berlesei, but not in $R$. robinii.
\end{abstract}

Keywords: Acaridae, fighting males, polymorphism, polyphenism.

\section{Introduction}

Male polymorphism occurs in several species of the mite family Acaridae (Acari: Astigmata) (Hughes, 1976; Woodring, 1969), yet only a few studies have addressed the problem of male morph determination (Foa, 1919; Woodring, 1969; Timms et al., 1981), giving often contradictory results. In most of the polymorphic species, there are two male morphs: fighter morphs have a thickened and sharply terminated third pair of legs which are used to puncture the cuticle of other males, while nonfighter morphs have unmodified legs.

However, Woodring (1969) describes four male morphs that occur in Acaridae, two of which are differentiated on the basis of the body shape. According to his classification, there are two basic body types: the homeotype, having a rounded body and short dorsal setae, and the bimotype, with a more elongated body and longer setae. The homeotype is further divided into the homeomorph (nonfighter, with unmodified legs) and the heteromorph (fighter, with thickened legs). The bimotype is divided into the bimorph (nonfighter) and the pleomorph (fighter). Although Woodring (1969) admitted that the homeotype/ bimotype distinction may be difficult to define in some species, he claimed that all four male types occur in Caloglyphus anomalus (Nesbitt).

\footnotetext{
*Present address (until September 1995): Max-Planck-Institut für Verhaltensphysiologie, D-82319 Seewiesen, Post Stamberg, Germany.
}

Acarid mites are diploid, with XO-type sex determination (though no sex chromosomes were observed in Rhizoglyphus echinopus Fumouse and Robin), males being the heterogametic sex, with parthenogenesis absent (Oliver, 1977). In the first study of male polymorphism in Acaridae, Foa (1919) concluded that in $R$. echinopus, in which both fighter and nonfighter males are found, male morph is determined at one locus and is inherited in a Mendelian fashion, the allele for thickened legs being dominant. Woodring (1969) distinguished two kinds of polymorphism in Acaridae. According to him, species exhibiting primary polymorphism (e.g. Caloglyphus berlesei (Michael), $C$. anomalus) show a regular ratio of fighters to nonfighters under specified environmental conditions, whereas in species exhibiting secondary polymorphism (e.g. C. bohartii), nonfighters occur almost exclusively in colonies, although fighter morphs may be obtained by isolating small numbers of larvae, proto- or young tritonymphs from stock cultures. Development of fighters may be suppressed by volatile substances emanating from dense colonies. In contrast to Foa's (1919) findings, Woodring (1969) listed $R$. echinopus as a species exhibiting secondary polymorphism, which suggests environmental rather than genetic determination of male morph.

Timms et al. (1980) showed that, contrary to Woodring's (1969) claim, the fighter morph was not observed in stock cultures of $C$. berlesei and was suppressed by airborne substances from dense cultures. They also found that male morph was not heritable (Timms et al., 1981). However, they selected 
as parents nonfighter males from dense colonies, whereas fighters were obtained by isolating individual larvae. On the other hand, they reported that a small proportion of nonfighters also developed from individually isolated larvae. It is possible, then, that nonfighter males from dense colonies carried 'genes for thickened' legs which were suppressed by the density effect, whereas nonfighters developing from isolated larvae could represent 'true nonfighter genotypes'. Thus, some degree of male morph heritability cannot be excluded on the basis of the results of Timms et al. (1981).

This paper presents the results of the study of male morph determination in two species of acarid mites: Caloglyphus berlesei (syn. Sancassania berlesei), in which bimorphic and pleomorphic males are represented, and Rhizoglyphus robinii (Cleparede), in which homeomorphic and heteromorphic males occur. The effects of paternal morph, density and diet were studied.

\section{Methods}

Both species of mites used in the experiments were derived from about 50 individuals collected from the field ( $R$. robinii from onions, and $C$. berlesei from poultry litter) several months earlier. They were kept at $>90$ per cent relative humidity at a stable temperature of $24^{\circ} \mathrm{C}$.

In breeding experiments, one virgin female and one male were placed in glass cells with plaster and charcoal bases and provided with food (3:1 mixture of powdered yeast and wheat-germ) ad libitum. One to two days later females started ovipositing in the cells. Hatched larvae were collected daily and each was placed into a separate cell to develop. The proportion of both male morphs was recorded for each cross.

Parents of $C$. berlese $i$ were isolated individually from the population at the stage of quiescent protonymphs (an instar preceding the tritonymphal stage at which a developmental switch occurs). Since such a procedure gives a very small proportion of nonfighter males, over 500 nymphs were isolated. Parents of $R$. robinii were isolated at the larval stage (because the timing of a developmental switch, if it occurs, was not known). An excess of larvae was isolated in order to determine the proportions of both morphs in the parental generation.

In experiments looking at the influence of density and diet on male morph development, protonymphs of both species were collected from stock cultures and placed in $0.8 \mathrm{~cm}$. diameter glass tubes either individually or in groups of 24. Individually isolated larvae were provided with either a rich diet (powdered yeast, Bovril Food Ingredients, Burton-on-Trent, U.K.) or a poor diet (filter paper, Gerson et al., 1983). The groups of 24 were fed yeast (henceforth referred to as yeast(24) treatment). An additional treatment in $R$. robinii consisted of providing individually isolated protonymphs with their natural food, onions. Random samples of about 20 males of each morph from each diet/density treatment were weighed on Sartorius Supermicro S4 scales (Sartorius $\mathrm{GmbH}$ ).

\section{Results}

\section{R. robinii}

The proportion of fighter males in $F_{1} s$ was higher in progenies sired by fighters (mean $=0.763, n=12$, range $0.39-1.00)$ than in those sired by nonfighters (mean $=0.351, n=12$, range $0.00-0.71$; MannWhitney $\left.U=12, n_{1}=n_{2}=12, P=0.001\right)$. This suggests a significant genetic factor in determining male morph. However, the results of some crosses are inconsistent with the single-locus inheritance suggested by Foa (1919) for R. echinopus (Fig. 1).

The proportion of fighters in the parental generation was $0.669(n=127)$. This value was used to estimate the heritability of male morphs as twice the regression of sons on fathers, as described by Falconer (1989) for threshold characters. Heritability was 98 per cent and 151 per cent for progenies sired by fighters and nonfighters, respectively.

Proportions of fighter males differed between diet/ density treatments (Table $1, \chi_{3}^{2}=70.7, P<0.001$ ). A multiple comparison test for proportions (Zar, 1984) revealed no significant differences between treatments in which mites developed on onion, yeast, or yeast in groups of 24 ( $P>0.2$ in all cases), but the proportion of fighters was smaller in comparison to other treatments when mites developed on filter paper $(P<0.001$ in all cases).

These results corresponded with differences in male body weight (Table 1): there were no significant differences between onion, yeast, and yeast (24) treatments $(P>0.8$ for all comparisons, Tukey-Kramer test), but males that developed on paper were significantly lighter than in other treatments $(P<0.001)$. Fighters and nonfighters did not differ significantly in their body weight in any of the treatments (Table 1; onion: $t=0.575, \quad P=0.569 ;$ yeast: $t=0.780, \quad P=0.439$; yeast(24): $\quad t=0.574, \quad P=0.568 ; \quad t$-test, pooled variances), though fighters tended to be heavier than nonfighters when males developed on filter paper (Table $1 ; t=2.201, P=0.09 ; t$-test, separate variances, adjusted d.f. $=4.2$ ).

\section{C. berlesei}

In $C$. berlesei, the proportions of fighter males in $F_{1}$ progenies sired by fighters (mean $=0.974, n=12$, 
Fig. 1 Numbers of male morphs in $F_{1} s$ shown on square-root transformed scales. On these co-ordinates, samples of all sizes have effectively the same standard error (Fisher and Mather, 1943; Mosteller and Tukey, 1949). Progenies of fighters (left) are shown separately from those of nonfighters (right). Thick lines represent ratios expected under a single-locus inheritance, with an allele for thickened legs dominant (upper graphs) or recessive (lower graphs). The expected ratios are $1: 0,3: 1$ or $1: 1$ if father morph is assumed to be dominant, and 1:0,1:1 and $0: 1$ if recessive. Thin lines delim $1 t$ a $5 \%$ two-tailed significance zone (Mosteller and Tukey, 1949) around $1: 1$ and $3: 1$ ratios (no variation is expected about 1:0 or 0:1 ratios). All points lying outside the zone were found to be significantly different from the expected ratios represented by solid lines $\left(\mathbf{P}<0.05\right.$ in all cases, $\chi^{2}$-test $)$.
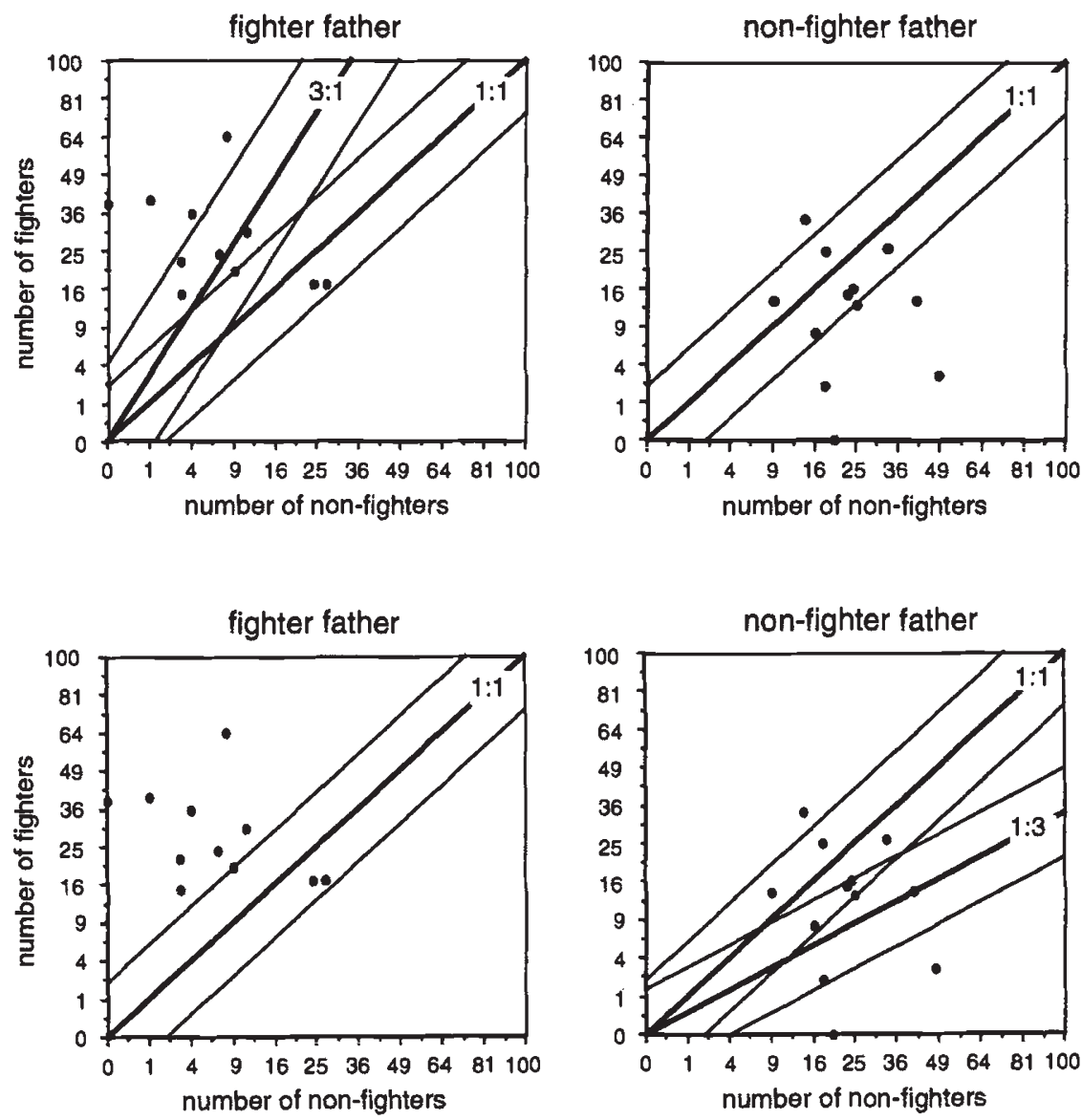

Table 1 Rhizoglyphus robinii: numbers $(N)$ and weights of fighter and nonfighter males in four diet/density treatments

\begin{tabular}{|c|c|c|c|c|c|c|c|c|}
\hline & \multicolumn{2}{|r|}{ Yeast } & \multicolumn{2}{|r|}{ Yeast(24) } & \multicolumn{2}{|r|}{ Onion } & \multicolumn{2}{|r|}{ Paper } \\
\hline & $N$ & $\begin{array}{c}\text { Weight }[\mathrm{mg}] \\
(\text { mean } \pm \mathrm{SD})\end{array}$ & $N$ & $\begin{array}{l}\text { Weight }[\mathrm{mg}] \\
(\text { mean } \pm \text { SD })\end{array}$ & $N$ & $\begin{array}{c}\text { Weight }[\mathrm{mg}] \\
(\text { mean } \pm \mathrm{SD})\end{array}$ & $N$ & $\begin{array}{c}\text { Weight [mg] } \\
\text { (mean } \pm \text { S.D.) }\end{array}$ \\
\hline Fighters & 49 & $\begin{array}{c}0.0319 \pm 0.0051 \\
(n=25)\end{array}$ & 51 & $\begin{array}{c}0.0324 \pm 0.0067 \\
(n=24)\end{array}$ & 45 & $\begin{array}{c}0.0330 \pm 0.0052 \\
(n=22)\end{array}$ & 5 & $\begin{array}{c}0.0199 \pm 0.0063 \\
(n=5)\end{array}$ \\
\hline Nonfighters & 28 & $\begin{array}{c}0.0333 \pm 0.0070 \\
(n=26)\end{array}$ & 22 & $\begin{array}{c}0.0337 \pm 0.0093 \\
(n=24)\end{array}$ & 18 & $\begin{array}{c}0.0339 \pm 0.0053 \\
(n=21)\end{array}$ & 57 & $\begin{array}{c}0.0137 \pm 0.0023 \\
(n=29)\end{array}$ \\
\hline Males pooled & & $\begin{array}{c}0.0326 \pm 0.0061 \\
(n=51)\end{array}$ & & $\begin{array}{c}0.0331 \pm 0.0081 \\
(n=48)\end{array}$ & & $\begin{array}{c}0.0335 \pm 0.0052 \\
(n=43)\end{array}$ & & $\begin{array}{c}0.0146 \pm 0.0038 \\
(n=34)\end{array}$ \\
\hline$P_{\mathrm{f}}$ & 0.636 & & 0.699 & & 0.714 & & 0.081 & \\
\hline
\end{tabular}

$P_{\mathrm{f}}$, proportion of figher males.

range $0.875-1$ ) did not differ significantly from those sired by nonfighters (mean $=0.969, n=9$, range 0.842-1; Mann-Whitney $U=58, \quad n_{1}=12, \quad n_{2}=9$, $P=0.745)$. This result, however, does not completely exclude a genetic basis for male polymorphism: if nonfighters were very rare recessive homozygotes, they might not be produced among a small number of crosses, since most females would be dominant homo- zygotes. Therefore, $F_{2}$ crosses were performed between a fighter male and a virgin female from each group of progeny. If nonfighters were recessive homozygotes, one would expect the proportion of fighters in nonfighter males' grandsons $\left(\mathrm{F}_{2}\right)$ to be 0.75 (assuming that offspring of nonfighters were heterozygotes). However, the results were similar to those obtained in the $F_{1}$ : the proportions of fighters in $F_{2}$ progenies 
derived from fighter $\mathrm{P}$ males $($ mean $=0.913, n=11$, range $0.706-1$ ) did not differ significantly from those derived from nonfighter $P$ males (mean $=0.921, n=9$, range $0.783-1$; Mann-Whitney $U=46, n_{1}=11$, $n_{2}=9, P=0.784$ ).

The proportions of fighters differed between diet/ density treatments (Table $2, \chi_{2}^{2}=136.8, P<0.001$ ). The differences were significant between all treatments $(P<0.001$; multiple comparison test for proportions (Zar, 1984)).

There was no significant difference in male body weight between yeast (only fighters' weights analysed) and yeast(24)(only nonfighters' weights) treatments (Table 2; $P=0.619$, Tukey-Kramer test), but males that developed on paper were significantly lighter than in the two other treatments $\quad P<0.001$ for both comparisons). Fighters that developed on paper were heavier than nonfighters fed the same diet (Table 2; $t=3.403, \quad P=0.010, \quad t$-test, separate variances, adjusted d.f. $=7.4$ ).

\section{Discussion}

The results of this study showed that male morph is determined in different ways in two species of acarid mites. In $R$, robinii the two morphs differ genetically. Although the results of some crosses were inconsistent with the single gene mechanism proposed by Foa (1919), heritability estimates exceeding 100 per cent suggest that a single major gene is responsible for male morph determination (Falconer, 1989). Further research using inbred strains will be necessary to clarify the system underlying male morph determination in $R$. robinii.
The departures from Mendelian ratios might be caused by limited gene penetrance under certain environmental (external) and/or physiological (internal) conditions. An example of an environmental factor is provided by this study: the proportion of fighters decreased when they developed on a poor diet. This suggests that nutritional stress, resulting in a decrease in body weight, can make production of thickened legs too costly for males. Alternatively, males may not invest in weapons (thickened legs) when they are too small to succeed in fights (Radwan, 1993a).

Those males that did develop into fighters on the poor diet seem to have coped better with the nutritional stress, as they tended to be larger than males that under the same conditons developed into nonfighters. This suggests that physiological competence to endure environmental stress may also play a role in male morph determination. It is conceivable that small differences between individuals, coupled with uncontrolled differences in rearing conditions, might have caused departures from Mendelian ratios in breeding experiments. It should be stressed, however, that these factors could not be responsible for the high father morph-son morph correlation observed in this study. The experimental design excluded the possibility of correlation arising from common environmental factors acting on both father and offspring, and there were no differences in weight between fighters and nonfighters when they developed on the same diet as was used during breeding experiments (i.e. yeast). Moreover, male morph heritability estimates exceeding 100 per cent could not be explained by a correlated response to selection on body size (Dominey, 1984) or

Table 2 Caloglyphus berlesei: numbers $(N)$ and weights of fighter and nonfighter males in three diet/density treatments

\begin{tabular}{|c|c|c|c|c|c|c|}
\hline & \multicolumn{2}{|c|}{ Yeast } & \multicolumn{2}{|c|}{ Yeast(24) } & \multicolumn{2}{|r|}{ Paper } \\
\hline & $N$ & $\begin{array}{c}\text { Weight [mg] } \\
(\text { mean } \pm \text { SD })\end{array}$ & $N$ & $\begin{array}{c}\text { Weight [mg] } \\
\text { (mean } \pm \text { SD) }\end{array}$ & $N$ & $\begin{array}{r}\text { Weight }[\mathrm{mg}] \\
(\text { mean } \pm \mathrm{SD})\end{array}$ \\
\hline Fighters & 70 & $\begin{array}{c}0.0437 \pm 0.0055 \\
(n=24)\end{array}$ & 2 & - & 7 & $\begin{array}{c}0.0315 \pm 0.0053 \\
(n=5)\end{array}$ \\
\hline Nonfighters & 2 & - & 61 & $\begin{array}{c}0.0455 \pm 0.0066 \\
(n=21)\end{array}$ & 34 & $\begin{array}{c}0.0219 \pm 0.0061 \\
(n=17)\end{array}$ \\
\hline Males pooled & & - & & - & & $\begin{array}{c}0.0241 \pm 0.0071 \\
(n=22)\end{array}$ \\
\hline$P_{\mathrm{f}}$ & 0.972 & & 0.032 & & 0.171 & \\
\hline
\end{tabular}

$P_{\mathrm{f}}$, proportion of pleomorphic males. 
physiological competence, because such traits are usually inherited quantitatively (Falconer, 1989).

The influence of diet on male morph expression was also documented by Woodring (1969) for C. anomalus, a species he selected to exemplify 'primary polymorphism', which may suggest genetic differences between male morphs. Also, temperature during development influenced the proportion of pleomorphs produced by $C$. anomalus.

In contrast to $R$. robinii, no evidence of a genetic basis for male morph determination was found in $C$. berlesei. The results of this study confirmed previous findings (Timms, 1980; Radwan, 1993b) that males are genetically equipotential and expression of one of the two morphs depends mainly on colony density. Also, poor diet was found to decrease the chance of a nymph developing into a fighter. Individuals that developed on poor diet were lighter than the ones reared on yeast. Fighters in the poor diet treatment were heavier than nonfighters in the same treatment, although there was no difference in body weight between fighters that developed in isolation on yeast and nonfighters that developed on yeast in groups. This suggests that a mechanism underlying suppression of the fighter morph in dense colonies is independent from the one observed in the poor diet treatment, even though a crowded environment may result in a decrease in body size (Radwan,1992). In fact, the suppression caused by increased density was significantly stronger than the suppression resulting from poor diet. Moreover, rearing nymphs of $R$. robinii in groups of the same size as those of $C$. berlesei had no effect on the proportion of fighter males that developed from them, but a poor diet effect was observed in both species.

Development of a particular male morph in a given social context in $C$. berlesei was shown to be adaptive (Radwan, 1993a). Fighters can kill all rival males and monopolize females if a colony is small, but in large populations they suffer higher mortality (because of fights) and achieve lower reproductive success than nonfighters. It remains to be seen whether similar selective pressures contribute to the maintenance of a genetically determined polymorphism in $R$. robinii. Further research is also needed to explain why adaptive matching of phenotype to environment has evolved in $C$. berlesei, but not in $R$. robinii. The absence of reliable cues during development, allowing prediction of the environment in which individuals will live as adults, has been proposed as a likely reason for the persistence of genetic polymorphism (Bradshaw, 1973; Moran, 1992).

\section{Acknowledgements}

I am grateful to W.D. Hamilton, S.J. Plaistow and an anonymous referee for their comments on the previous version of the manuscript.

\section{References}

BRADSHAW, W. E. 1973. Homeostasis and polymorphism in vernal development of Chaoborus americanus. Ecology, 54, 1247-1259.

DOMINEY, w. J. 1984. Alternative mating tactics and evolutionary stable strategies. Am. Zool., 24, 385-396.

FALCONER, D. S. 1989. Introduction to Quantitative Genetics. 3rd ed. Longman Scientific \& Technical, Harlow, Essex.

FISHER, R. A. AND MATHER, K. 1943. The distribution of style length in Lythrum salicaria. Ann. Eugen., 12, 1-23.

FOA, A. 1919. Studio del polimorfismo unisessuale del Rhizolyphus echinopus. Memoria Accad. Pontificia Nuovi Lincei. Roma Ser. V, 12, 3-109.

GERSON, U., CAPUA, S. AND THORENS, D. 1983. Life history and life tables of Rhizoglyphus robinii Cleparede (Acari: Astigmata: Acaridae). Acarologia, 24, 439-448.

hughes, A. M. 1976. The Mites of Stored Food and Houses. Technical Bulletin No. 9. Ministry of Agriculture, Fisheries and Food, London.

MORAN, N. A. 1992. The evolutionary maintenance of alternative phenotypes. Am. Nat., 139, 971-989.

MOSTELLER, F. AND TUKEY, J. W. 1949. The uses and usefulness of binomial probability paper. J. Am. Stat. Ass., 44, 174-212.

OLIVER, J. H., Jr. 1977. Cytogenetics of mites and ticks. Ann. Rev. Ent., 22, 407-429.

RADWAN, J. 1992. The influence of a crowded environment on the size of males of Caloglyphus berlesei (Acari: Acaridae). Int. J. Acarol., 18, 67-68.

RADWAN, J. 1993a. The adaptive significance of male polymorphism in the acarid mite Caloglyphus berlesei. Behav. Ecol. Sociobiol., 33, 201-208.

RADWAN, J. 1993b. Kin recognition in the acarid mite, Caloglyphus berlesei - negative evidence. Anim. Behav., 45, 200-202.

TIMMS, S., FERRO, D. N. AND EMBERSON, R. M. 1981. Andropolymorphism and its heritability in Sancassania berlesei (Michael) (Acari: Acaridae). Acarologia, 22, 391-398.

TIMMS, S., FERRo, D. N. AND WALLER, J. B. 1980. Suppression of production of pleomorphic males in Sancassania berlesei (Michael) (Acari: Acaridae). Int. J. Acarol., 6, 91-96.

wooDRING, J. P. 1969. Environmental regulation of andropolymorphism in Tyroglyphids (Acari). In: Evans, G.O. (ed.) Proceedings of the 2nd International Congress of Acarology, pp. 433-440. Akademiai Kiado, Budapest.

ZAR, J. H. 1984. Biostatistical Analysis. Prentice-Hall, Englewood Cliffs, NJ. 